\title{
The Effect of Adopting Technology in Intellectual Capital
}

\author{
Mustafa Abdullah Mohammed ${ }^{1}$, Abbas Ali Muhammad ${ }^{2}$, Alhamzah Alnoor ${ }^{3}$, Marwa Al- \\ Maatoq ${ }^{4}$ \\ \{m.abdulla@stu.edu.iq ${ }^{1}$,ma425770@gmail.com², alhamzah.malik@stu.edu.iq ${ }^{3}$, \\ marwamousa993@gmail.com $\left.{ }^{4}\right\}$ \\ Southern Technical University, Management Technical College-Iraq ${ }^{1,4}$ \\ Office of High Commissioner for Human Rights, Basrah, Iraq ${ }^{2}$ \\ School of Management, Universiti Sains Malaysia, 11800 Pulau Pinang, Malaysia ${ }^{3}$
}

\begin{abstract}
This research seeks to provide a practical and theoretical framework on the subject of "the impact of the use of information technology in enhancing the performance of human resources." The hypothetical study plan was tested in the private sector in the province of Basra, and it includes several contracting companies. The questionnaire and the personal interview were used as a data collection method for the study, and the sample size was 213 employees. Several statistical methods were used to test the study hypotheses. The results concluded that there is an impact of information technology on the performance of human resources. Some studies have addressed these variables in the service sector because of their importance in all countries. Further studies in other sectors and the introduction of other variables are needed.
\end{abstract}

Keywords: Information technology, performance, human resources

\section{Introduction}

All organizations operating in various economic, industrial, commercial, and service sectors private as well as public depend on today to a large extent on information technology to accomplish their tasks and achieve their goals, through the ability of information technology to achieve many opportunities for all organizations represented by (reducing costs and making a decision, analysis, communication, and feedback) that are employed by those organizations in the field of (accounting, finance, research and development, operations management, marketing, human resource management) or any other business function (Alpar \& Kim, 1990).

Also, the developments in the field of (IT) and its low costs helped organizations a lot to adapt and employ it in their work by investing very large amounts in the field of IT, which proved its ability to give economic value to the business (Raymond \& Paré, 1992). Expressed by increasing competitiveness and high productivity, and thus increasing returns. In some developed countries, their budgets have shown the number of large sums invested in the field of (IT) (Hyvönen, 2007). In 2010, the United States of America spent more than $\$ 562$ billion on (hardware, software) software, wired and non-wired telecommunications equipment) as well as its intention to spend $\$ 800$ billion on business consulting, management, and services, much of which involves redesigning corporate business processes to take advantage of this new technology (Otim et al., 2012; Ding, 2014). Accordingly, based on the importance of the topics 
of the study, and in continuity with previous research efforts in increasing intellectual enrichment in these topics, this study came to focus on the following question: "what extent is information technology available in contracting companies that enhances the performance of human resources?"

\section{Literature Review}

\subsection{Information technology}

The use of the word technology has increased dramatically during the twentieth century until this concept expanded and included several concepts of technology (Kim \& Lee, 2006). It includes tools, machines, equipment, weapons, all means and material tools for technical performance. Thus, all the experiences that were created for technical and artistic innovation are the know-how. Moreover, it is what people do, their skills, the methods they use, the procedures they perform, the routine of work. In addition, it is the manufacture and use of things, which include people themselves and other things as a group or as a combination (one unit). According to (DeLone \& McLean, 2016) as the material means, methods, technical processes, and skills to transform inputs such as (materials, knowledge, capital, energy) into outputs represented by (goods and services). The word technology may be of two syllables, the first TECHNO meaning (art, workmanship, technical). As for the second syllable, it is LOGY meaning (doctrine, science, theory). If the two words meet in one word, we find that every art or craft must be framed by science or a certain scientific theory (Grigoriev \& Teleshevskii, 2011). It is an effective tool for the achievement and development of administrative processes in all organizations and includes a set of devices, equipment, software, communications, and the human element, whose adoption entails collecting and processing data on the activities of the organization, storing information, processing, retrieval and updating it at an economic cost, high flexibility, and relatively fast speed to respond to the requirements of its beneficiaries to form Competitive advantage of the organization (Segars, 1997).

Information technology represents the physical components of devices and their accessories such as the monitor, keyboard, printer, and others. Also, computer software, which are invisible components that manage computer resources, process, store, retrieve and transfer data. A computer consists of the following main parts, the physical components of a computer system (Agarwal \& Prasad, 1998). However, the central processing unit (CPU) is one of the most important parts of the computer, where the computer is linked with the input and output units, and its most important functions are to perform arithmetic and logical operations, storage, control, monitoring and routing (Nguyen, 2009). On the other hand, the software consists of computer programs of the System Software category and the Application Software category. Investment in the field of information technology and its applications in various business fields requires directing resources towards the communication network that links data processing systems, operations, database management systems, and direct service points to the end beneficiary. Therefore, the Internet is a global network of information that includes large pockets of erased networks distributed throughout the world (McAfee, 2002). The Intranet is a private corporate network that uses internet technologies that are designed to meet the needs of employees for internal information or the exchange of data and information about operations and activities of the organization ( $\operatorname{Rad}$ et al., 2018). 


\subsection{HR Performance}

Performance reflects the organization's ability to achieve its near and long-term goals, which are represented in survival, growth, and adaptation by using its available resources, with high efficiency and effectiveness, and based on quality and reaching the satisfaction of stakeholders (Soltani et al., 2014). There is no agreement on the concept of performance among researchers in management science, and this difference is reinforced by the different criteria and standards adopted in the study and measurement of performance (Chow, 2012). The concept of performance is defined as the management's ability to transform the inputs into the organization's own into several outputs with specifications and the lowest possible cost. Based on previous studies it is the outcome of using the available inputs in a group of activities accomplished by the working individual, which are carried out consciously and consciously during a specific time measured by the prevailing unit of work (Wright et al., 2003). Also, it referred to the concept of performance as obligating the technical and administrative workers to provide their best achievement (Van De Voorde \& Beijer, 2015).

Researchers differed in determining the dimensions of human resource performance. And productivity, liquidity ratio, and turnover ratio (Soltani et al., 2014), while others depended on the link between behavioural and economic indicators, including social responsibility, increasing profits, work turnover, sales growth, and market share (Al-Musadieq et al., 2018). The performance of human resources consists of two basic dimensions, which are the organizational dimension, which means the methods and mechanisms adopted by organizations in the organizational field to achieve their goals. As for the social dimension of management, it refers to the extent to which satisfaction is achieved among stakeholders in the organization (Beltrán-Martín \& Bou-Llusar, 2018). In conclusion, the dimensions of human resource performance consist of Efficiency, which is the ability and perfection to achieve the specified goal, meaning to increase to the highest possible extent the results or outputs compared to the inputs. Effectiveness is immediate efficiency, adaptability to future goals, meaning doing the right things. Finally, quality is the production of a product or service that meets the needs and recommendations of customers, i.e., the solution to the satisfaction achieved by stakeholders because of meeting their needs (Khoreva \& Wechtler, 2018).

\subsection{The Relationship Between Information Technology and HR Performance}

Research and studies have shown a positive relationship between information technology and decision-making (Kryscynski et al., 2018). Where the positive results were on the various dimensions and levels of decisions. The positive impact of information technology was reflected on the quality of the decision (Kassar \& Singh, 2019), as well as on the decision-making process. Through its role in providing accurate and timely information in a way that enhances the positive interaction between the members of the organization and the data collected. IT can also affect the stage of mental thinking, as well as its impact on the stages of the decision-making process such as design, selection, and implementation (Van De Voorde \& Beijer, 2015). This is due to the ability of information technology to reduce bias by providing objective and logical information (Sharma \& Sharma, 2017). It also has a role in providing managers with the necessary information at the various necessary administrative levels.

IT has a fundamental and renewed role in increasing the effectiveness of organizational communication by reducing the time it takes to access information for decision making (Kryscynski et al., 2018). Through its great impact on internal communications, so that it increases its efficiency and effectiveness and transcends the limits of time and place (Silva et 
al., 2017). Besides, the use of IT is positively related to horizontal communication patterns to increase the effectiveness of empowerment and to enable managers to make decisions at the lower level (Brockbank et al., 2018). IT helps to pass quickly access to large amounts of information faster and easier than before (Gupta et al., 2019), especially considering the development of e-mail as one of the communication channels emanating from information technology. The close relationship between IT and the means of organizational communication, as the linking of hardware components (computers), software and their applications, and networks of IT with systems such as the Internet and Intranet to create a computerized environment for easy access to information, thus, creating effective and rapid communication and information exchange (Sekhar et al., 2017). Hence, the study assumes that IT affects organizational communication and its sub-dimensions: official books, e-mail, intranet, meetings (Al Qalhati et al., 2020). Based on the previous discussion, it can be assumed:

H1: There is an influence relationship between information technology and efficiency.

H2: There is an influence relationship between information technology and effectiveness.

H3: There is an influence relationship between information technology and

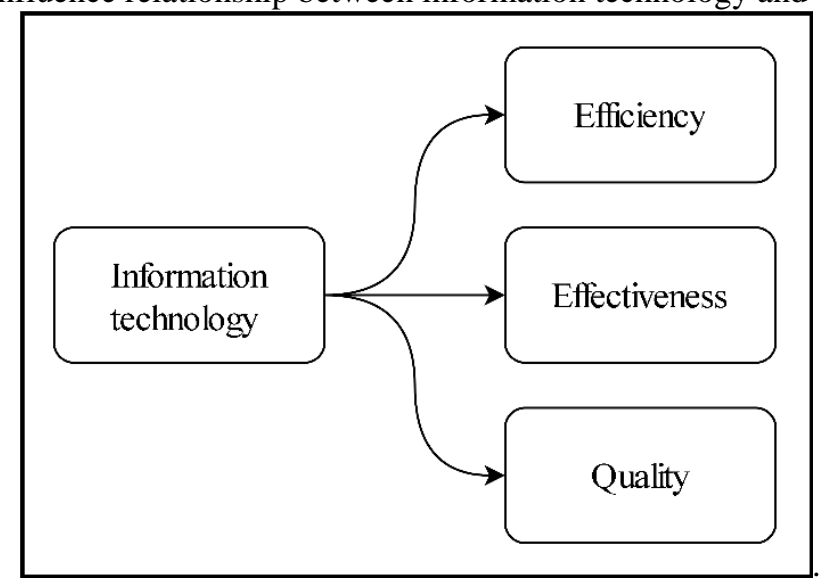

Fig. 1. Conceptual Framework.

\section{Methodology}

Through a review of the previous administrative literature, the researcher found a few studies that employed this approach (the use of information technology) in studying the performance of human resources, especially in the private sector, so this study is a new contribution within the Iraqi environment. In addition, most of the previous studies tried to focus on single dimensions such as the relationship between the use of information technology and organizational citizenship behaviour or the use of information technology and human resource performance, while this study will present an integrative model. Therefore, this study targeted an exploratory design. The design of the study indicates that it is the development of plans to collect information based on time and the research question, which provides evidence for data and information collection, and establishes a framework for determining the relationships between variables. The problem posed is that the design of this study adopted an exploratory design. Moreover, the hypothetical study plan was tested in the private sector in the province of 
Basra, and it includes several contracting companies. The questionnaire and the personal interview were used as a data collection method for the study, and the sample size was 213 employees. The questionnaire is the basic source for data collection, which is a set of questions that the respondent records his answer to, usually by choosing one of the specified alternatives. The questionnaire was relied upon due to the researcher's accurate knowledge of what was required and how to measure the variables to be studied, and the (Likert) quintuple scale was relied upon, which is graded according to the following answers (strongly disagree " 1 ", disagree " 2 ", agree to some extent "3", Agree "4", strongly agree "5"). This study has used a scale of information technology based on (Luftman et al., 2017), to measure information technology and included 12 items, while the dependent variable (i.e., human resource management) was measured by adopted12 items (Alnoor, 2020). Hence, the final sample consisted of 124 administrators and 89 , representing $64 \%$ of males and $36 \%$ of females. Those with a diploma represented the majority at a rate of $32 \%$, while the percentage of those who obtained a bachelor's degree was $47 \%$ of the sample, masters, and doctorates were $21 \%$.

\section{Data analysis}

We have used SEM-Modelling structural equations (SEM) in the current study to evaluate the Model-fit. It is by confronting the models dependent on multiple indicators and choose the better model. The results in Table 1 were obtained through Amos v .23. The reliable indicators are, first, RMSEA-root mean square error of approximation, and SRMR-standardized root means square residual, which both must be lower than 0.08 (Arbuckle, 2006). Secund, CFIcomparative fit index; IFI-incremental fit index; and NFI-normed fit index, its value must $\geq 0.90$. Third, the ratio between X2Chi-square and df-degree of freedom, which must be lower than 2.5 (Arbuckle, 2006). We were an exam the single-factor (M1) this is done by linking all the variables to a single latent factor; the results were $(\mathrm{X} 2 / \mathrm{df}=2.109$; $\mathrm{CFI}=.646$; $\mathrm{IFI}=.496$; NFI=.785; RMSEA=.163, Then, we was exam the two-factor (M2), innovation was identified as the first latent factor and the rest of the variables loading on innovation, the results were $(\mathrm{X} 2 / \mathrm{df}=1.468 ; \mathrm{CFI}=.962 ; \mathrm{IFI}=.957 ; \mathrm{NFI}=.952 ; \mathrm{RMSEA}=.078)$. Table 1 summarizes the results for three models, as a model (M3) comparing other models is better.

Table 1. Assessing the model's fit.

\begin{tabular}{cccccc}
\hline Models & CFI & IFI & NFI & RMSEA & X²/df $^{2}$ \\
\hline M1 & .646 & .496 & .785 & .163 & 2.109 \\
\hline M2 & .962 & .957 & .952 & .078 & 1.468 \\
\hline
\end{tabular}

In Table 2, the results show descriptive statistics that have means, SD-standard deviations, and correlations test between the study variables. Correlation coefficients between the variables are lower than (0.5). They thus do not indicate the multicollinearity problems; this also suggests that the independent variables do not overlap, which leads to the difficulty of measuring the effect of the independent variable on the function. Also, the Cronbach's alpha test was used to verify the reliability of study measures and their internal consistency. Table 2 shows that the values of Cronbach's alpha are more significant than 0.70 ; they are statistically acceptable in 
managerial and behavioural studies (Pallant, 2020). Finally, these results support the hypotheses of the study.

Table 2. Descriptive statistics, correlations, and reliability

\begin{tabular}{lcccccc}
\hline Variables & Mean & SD & 1 & 2 & 3 & 4 \\
\hline 1-Information technology & 3.34 & .864 & 1 & & & \\
2- Efficiency & 3.56 & .903 & $.386^{* *}$ & 1 & & \\
3- Effectiveness & 3.35 & .922 & $.332^{* *}$ & $.129^{* *}$ & 1 & \\
4-Quality & 3.57 & .996 & $.595^{* *}$ & $.306^{* *}$ & $.465^{* *}$ & 1 \\
\hline
\end{tabular}

Amos was used to analysing the hypotheses of the current study model. Also, the Bootstrapping tool was used to test the level of significance of the indirect effects, and it is a robust tool and is widely used in similar studies.

Table 3. Testing hypotheses.

\begin{tabular}{|l|c|c|c|c|c|c|}
\hline \multicolumn{2}{|c|}{ Path } & Estimate & C.R & P & Label \\
\hline Information technology & $\rightarrow$ & Efficiency & 0.328 & 5.246 & 0.000 & Supported \\
\hline Information technology & $\rightarrow$ & Effectiveness & 0.210 & 8.609 & 0.000 & Supported \\
\hline Information technology & $\grave{a ̀}$ & Quality & 0.127 & 9.336 & 0.000 & Supported \\
\hline Information technology & $\grave{a ̀ ~}$ & Human resource & 0.278 & 9.085 & 0.000 & Supported \\
\hline
\end{tabular}

Based on the path coefficients built in the above table using PLS-SEM, it is clear that most of the study hypotheses are supported as the critical success factors. Hence, there is a positive impact of information technology on human resource performance.

\section{Discussion}

The results reached by the researcher were based on answering the objectives and hypotheses of the research, which were formulated by reviewing the literature related to this topic, and through the data collected through the use of each of the private interviews with several general managers in contracting companies, as well as data collection through The questionnaire form, which included general managers and their assistants, department managers and divisional officials in several companies. Therefore, the results indicated the great role that information technology plays in the college, the study sample, in good proportions. The answers of the sample members for all the paragraphs related to this axis and its sub-dimensions were in good agreement, which indicates the companies' use of software related to their activities and their possession of devices, equipment, technical human resources, and communication networks to accomplish the basic college tasks, and thus provide an acceptable service. The results also showed the existence of a correlation and impact relationship between information technology in its dimensions and the performance of human resources, and these results are consistent with the results reached by each, as information technology currently contributes significantly to the completion of the basic tasks, functions, and activities of the college by providing data and information with the required speed and accuracy. The results of the current study reinforced the results of previous studies regarding the existence of a positive correlation 
and the impact of information technology with its dimensions on the performance of human resources, as it helped to transcend the limits of spatial and temporal considerations and fundamentally affected the mechanism of companies' work, by enhancing the role of organizational communications represented by the intranet and e-mail (Internet), and it was consistent with the findings of the study by increasing the volume of the transmitted information and the possibility of disseminating it to wider ranges in a very short time. And then, through observation and interviews with several general managers, heads of departments, and people, there appeared the response of the organizational structures of the research sample companies to information technology within their organizational structures. Finally, the results showed the existence of an indirect positive correlation and impact of information technology on organizational performance and thus making accurate and objective decisions. While through complexity, information technology helps to provide information from various functional departments and administrative levels quickly and accurately, thus overcoming the obstacles facing decision-makers due to the diversity and complexity of tasks.

\section{Limitation and Future Research}

This study includes some limitations, as in other studies that can be handle in future studies. The current study focused on the contracting industry sector, there is a need to conduct more studies on other areas such as other industrial sectors or the service sector. The current study is cross-sectional, so longitudinal studies are required to support the results of the present study with more reliable results. Regarding the variables, it is possible to think about variables that fall outside the employee's mind or composition such as leadership or entrepreneurial culture, and therefore there is a need to support the current model with influencing environmental variables. These are the condition for learning and innovation. The aim of the study was the changes that occurred in the contracting industry in southern Iraq, a comparative study between the results of the current research and education in other countries that are culturally different from Iraq will provide us with more results to clarify the problem. This study includes some limitations that can be handle in future studies. The current study focused on the electric power projects industry sector, so there is a need to conduct more studies on other industries or the service sector. The other limitation is the lack of data. The panel data analysis could bring more accurate results. The current study is cross-sectional, so longitudinal investigation would be more advanced to support the results of the present study with more reliable results.

\section{Conclusion}

It is possible to identify the most important recommendations that resulted from the study and based on the results of the study analysis and the conclusions that were reached, we recommend the importance of directing the higher departments in the college under research towards expanding the adoption of information technology, as it is a tool that leads to making its organizational structures more flexible to adapt to current and future work requirements, through Providing its administrative units with administrative and technical competencies capable of playing its pivotal role, and enhancing its annual budget so that it can improve its systems of hardware components (computers) and advanced software, and grant it sufficient independence in making its decisions regarding its activities and tasks. We suggest expanding 
reliance on the use of the Internet, intranet, and other information technology tools, to approximate the distance between the college headquarters and the affiliated departments and geographically dispersed in the governorates of the country on the one hand, and the other hand, working on the most accurate data and information in the fastest time and at the lowest cost. Because of the negative result of the study of the weak influence of communication networks on decision-making, and through personal interviews, it is due to the companies under research, or rather all Iraqi organizations, relying on the official books issued by the ministry or other ministries when taking an action or decision. Without relying on the intranet or the Internet as an official tool to transfer correspondence between them. Moreover, based on the results of the analysis of the weak relationship and negative impact value between data and organizational communication, so we suggest that the relevant authorities pay attention to databases in terms of data volume and quality, and by enhancing them with appropriate software capable of processing information with appropriate speed and accuracy. And the use of organizational communication as a primary channel for transmitting data to be invested in making quick and accurate decisions. Also, because the human element represents the effective tool in the perpetuation of the role of information technology in the work of the researched companies, so we recommend paying attention to the establishment of specialized courses in the field of information technology to raise the level of skill and knowledge capabilities to address technical problems and make updates in the operating systems. Finally, this study suggests an attempt to raise the level of the role of information technology from being a tool used to overcome obstacles and enhance opportunities for the college to improve the services provided, and because of its positive impact on all functional departments in the researched companies to making it a real partner in all programs from preparing strategic plans and setting policies and executive programs.

\section{References}

[1] Agarwal, R., \& Prasad, J. (1998). The antecedents and consequents of user perceptions in information technology adoption. Decision support systems, 22(1), 15-29.

[2] Al Qalhati, N., Karim, A. M., Al Mughairi, B., Al Hilali, K., \& Hossain, M. I. (2020). Technology and HR Practices in Educational Sector in Sharqiya Governate of Oman. International Journal of Academic Research in Business and Social Sciences, 10(10), 435-443.

[3] Al-Musadieq, M., Nurjannah, N., Raharjo, K., Solimun, S., \& Fernandes, A. A. R. (2018). The mediating effect of work motivation on the influence of job design and organizational culture against HR performance. Journal of Management Development.

[4] Alnoor, A. (2020). Human capital dimensions and firm performance, mediating role of knowledge management. International Journal of Business Excellence, 20(2), 149-168.

[5] Alpar, P., \& Kim, M. (1990). A microeconomic approach to the measurement of information technology value. Journal of Management Information Systems, 7(2), 55-69.

[6] Arbuckle, J. (2006). Amos 7.0 user's guide. Springhouse, PA: Amos Development Corporation.

[7] Beltrán-Martín, I., \& Bou-Llusar, J. C. (2018). Examining the intermediate role of employee abilities, motivation and opportunities to participate in the relationship between HR bundles and employee performance. BRQ Business Research Quarterly, 21(2), 99-110.

[8] Brockbank, W., Ulrich, D., Kryscynski, D. G., \& Ulrich, M. (2018). The future of HR and information capability. Strategic HR Review.

[9] Chow, I. H. S. (2012). The roles of implementation and organizational culture in the HR-performance link. The International Journal of Human Resource Management, 23(15), 3114-3132.

[10] DeLone, W. H., \& McLean, E. R. (2016). Information systems success measurement. Foundations and Trends ${ }^{\circledR}$ in Information Systems, 2(1), 1-116.

[11] Ding, F. (2014). Hierarchical estimation algorithms for multivariable systems using measurement information. Information Sciences, 277, 396-405. 
[12] El-Kassar, A. N., \& Singh, S. K. (2019). Green innovation and organizational performance: the influence of big data and the moderating role of management commitment and HR practices. Technological Forecasting and Social Change, 144, 483-498.

[13] Grigoriev, S. N., \& Teleshevskii, V. I. (2011). Measurement problems in technological shaping processes. Measurement techniques, 54(7), 744-749.

[14] Gupta, S., Kumar, S., Kamboj, S., Bhushan, B., \& Luo, Z. (2019). Impact of IS agility and HR systems on job satisfaction: an organizational information processing theory perspective. Journal of Knowledge Management.

[15] Hyvönen, J. (2007). Strategy, performance measurement techniques and information technology of the firm and their links to organizational performance. Management Accounting Research, 18(3), 343-366.

[16] Khoreva, V., \& Wechtler, H. (2018). HR practices and employee performance: the mediating role of well-being. Employee Relations.

[17] Kim, Y., \& Lee, K. (2006, November). A quality measurement method of context information in ubiquitous environments. In 2006 International Conference on Hybrid Information Technology (Vol. 2, pp. 576-581). IEEE.

[18] Kryscynski, D., Reeves, C., Stice-Lusvardi, R., Ulrich, M., \& Russell, G. (2018). Analytical abilities and the performance of HR professionals. Human Resource Management, 57(3), 715-738.

[19] Luftman, J., Lyytinen, K., \& Zvi, T. B. (2017). Enhancing the measurement of information technology (IT) business alignment and its influence on company performance. Journal of Information Technology, 32(1), 26-46.

[20] McAfee, A. (2002). The impact of enterprise information technology adoption on operational performance: An empirical investigation. Production and operations management, 11(1), 33-53.

[21] Nguyen, T. H. (2009). Information technology adoption in SMEs: an integrated framework. International Journal of Entrepreneurial Behavior \& Research.

[22] Otim, S., Dow, K. E., Grover, V., \& Wong, J. A. (2012). The impact of information technology investments on downside risk of the firm: Alternative measurement of the business value of IT. Journal of Management Information Systems, 29(1), 159-194.

[23] Pallant, J. (2020). SPSS survival manual: A step by step guide to data analysis using IBM SPSS. Routledge.

[24] Rad, M. S., Nilashi, M., \& Dahlan, H. M. (2018). Information technology adoption: a review of the literature and classification. Universal Access in the Information Society, 17(2), 361-390.

[25] Raymond, L., \& Paré, G. (1992). Measurement of information technology sophistication in small manufacturing businesses. Information Resources Management Journal (IRMJ), 5(2), 4-16.

[26] Segars, A. H. (1997). Assessing the unidimensionality of measurement: A paradigm and illustration within the context of information systems research. Omega, 25(1), 107-121.

[27] Sekhar, C., Patwardhan, M., \& Vyas, V. (2017). Causal modelling of HR flexibility and firm performance in Indian IT industries. Journal of Modelling in Management.

[28] Sharma, A., \& Sharma, T. (2017). HR analytics and performance appraisal system. Management Research Review.

[29] Silva, A., Varajão, J., Pinto, C. S., \& e Sá, J. O. (2017, April). Who can assess HR performance in IT/IS projects: a review. In World Conference on Information Systems and Technologies (pp. 779789). Springer, Cham.

[30] Soltani, E., Gennard, J., Van der Meer, R. B., \& Williams, T. (2004). HR performance evaluation in the context of TQM. International Journal of Quality \& Reliability Management.

[31] Van De Voorde, K., \& Beijer, S. (2015). The role of employee HR attributions in the relationship between high-performance work systems and employee outcomes. Human Resource Management Journal, 25(1), 62-78.

[32] Wright, P. M., Gardner, T. M., \& Moynihan, L. M. (2003). The impact of HR practices on the performance of business units. Human resource management journal, 13(3), 21-36. 


\section{Questionnaire}

\section{A. Information technology}

1. The devices used in information technology are the best and most modern currently.

2. The devices used are commensurate with the company's business and functions.

3. The computer helps a lot in solving the problems that I face in my work.

4. Computer programs are suitable for carrying out the company's tasks.

5. I find it easy to use computer programs.

6. The applied software helps to achieve in college.

7. I can get the required information within the databases.

8. I use the database to search for information.

9. You find the existing database useful to you and your department.

10. The available communication allows the exchange of information between employees

11. I can use the Internet to get things done more quickly

12. The use of the Internet helps to facilitate the completion of work.

\section{B. Human resource performance}

1. Complete the work according to the available resources.

2. Reducing the wastage of all kinds of resources.

3. Complete the work within the time.

4. A reduction in labor-related costs.

5. The ability to adapt to various environmental conditions.

6. Achieving well-established general goals.

7. Have plans and procedures that can positively deal with changes.

8. Encouraging senior management to support and disseminate quality.

9. Have the necessary human resources to help support quality.

10. Assisting in setting quality as a criterion for determining the value of individual.

11. Develop and implement long-term plans to provide high quality services to customers.

12. The company provides support for the implementation of strategic plans. 